Bull. Chem. Soc. Ethiop. 2017, 31(2), 233-240.

ISSN 1011-3924

(C) 2017 Chemical Society of Ethiopia and The Authors

Printed in Ethiopia

DOI: http://dx.doi.org/10.4314/bcse.v31i2.5

\title{
DIRECT GROWTH OF VERTICALLY ALIGNED CARBON NANOTUBES ON SILICON SUBSTRATE BY SPRAY PYROLYSIS OF GLYCINE MAX OIL
}

\author{
K.T. Karthikeyan ${ }^{1}$, V.S. Angulakshmi ${ }^{2 *}$, S. Karthikeyan ${ }^{3}$, K. Jothivenkatachalam ${ }^{4}$ and P.A. \\ Ananda Kumar ${ }^{5}$ \\ ${ }^{1}$ Department of Chemistry, M.A.M. College of Engineering, Trichy, TN, India \\ ${ }^{2}$ Department of Chemistry, Kathir college of Engineering, Coimbatore, TN, India \\ ${ }^{3}$ Department of Chemistry, Chikkanna Government Arts College, Tripur, TN, India \\ ${ }^{4}$ Department of Chemistry, BIT campus, Anna University, Trichy, TN, India \\ ${ }^{5}$ Department of Mechanical Engineering, Dilla University, Semera Campus, Ethiopia
}

(Received April 26, 2015; revised July 26, 2017)

\begin{abstract}
Vertically aligned carbon nanotubes have been synthesized by spray pyrolysis from Glycine max oil on silicon substrate using ferrocene as catalyst at $650{ }^{\circ} \mathrm{C}$. Glycine max oil, a plant-based hydrocarbon precursor was used as a source of carbon and argon as a carrier gas. The as-grown vertically aligned carbon nanotubes were characterized by scanning electron microscopy, high-resolution transmission electron microscopy, X-ray diffraction, thermogravimetric analysis, and Raman spectroscopy. Scanning electron microscopic images reveal that the dense bundles of aligned carbon nanotubes. High resolution transmission electron microscopy and Raman spectroscopy observations indicate that as-grown aligned carbon nanotubes are well graphitized.
\end{abstract}

KEY WORDS: Spray pyrolysis, Vertically aligned CNT, Ferrocene, Silicon substrate

\section{INTRODUCTION}

Vertically aligned carbon nanotubes are quasi-dimensional carbon cylinders that align perpendicular to a substrate [1]. Aligned carbon nanotubes represent an important architecture of CNTs because they can be used directly as field emitters in flat panel displays as reinforcing agents in composite materials [2,3]. Furthermore, vertically aligned carbon nanotubes also exhibit a high capability to produce high current densities under low operating voltages [4]. Aligned carbon nanotubes possessing larger surface area and higher electrical conductivity over entangled CNTs, are ideal electrode material for DNA biosensor [5], energy storage device [6], sensors for glucose [7], $\mathrm{pH}$ [8] as well as $\mathrm{NO}_{2}$ [9]. Jung et al. demonstrated laser transmission welding of vertically aligned carbon nanotube arrays for joining polymer sheets [10]. Aligned carbon nanotubes reported by Thess et al. were able to bundle $70 \%$ of the volume of nanotubes into crystalline ropes in 1996 [11]. Fan et al. introduced position controlled growth of vertically aligned CNT on porous and plain silicon substrate [12]. CNT arrays have successfully grown on different substrates such as quartz substrate [13], planar silicon substrate [14]. Ferrocene and its derivatives are significant as regards biological applications [15]. Ferrocene has been shown to be a good precursor of iron nanoparticles suitable to catalyze CNT growth [16-17]. Conventionally hydrocarbons such as methane, ethane, ethylene, acetylene, xylene and ethanol were used as a carbon source for the synthesis of CNTs [18-23]. The number of studies utilizing low-cost carbon sources for the synthesis of CNTs such as botanical hydrocarbon is very limited [24-28]. Afre et al. have used spray pyrolysis method and prepared aligned carbon nanotubes from ferrocene and turpentine oil mixture on quartz and silicon substrates [29]. Instead of using conventional petro chemicals, we rather use a natural precursor - Glycine max oil. From our previous study it is proved that Glycine max oil have been found to be an efficient precursor of

*Corresponding author. E-mail: angulakshmiprabu@gmail.com

This work is licensed under the Creative Commons Attribution 4.0 International License 
multiwalled carbon nanotubes. We have reported the fabrication of multiwalled carbon nanotubes using the same precursor with $\mathrm{Fe} / \mathrm{Mo}$ as catalyst under nitrogen atmosphere [30]. This article explains the simple method for synthesis of vertically aligned CNTs on silicon substrate using Glycine max oil as carbon source by spray pyrolysis method using ferrocene as a catalyst. The results show that Glycine max oil as potential green precursor of vertically aligned CNTs.

\section{EXPERIMENTAL}

Vertically aligned CNTs were grown by spray pyrolysis method using Glycine max oil and ferrocene as catalyst. In this method, pyrolysis of the carbon precursor and catalyst takes place simultaneously. Glycine max oil was used as carbon source. Ferrocene was used as a source of $\mathrm{Fe}$ which acts as a catalyst for the growth of CNTs. Silicon substrates of dimension of $1 \mathrm{~cm} \mathrm{x} 1$ $\mathrm{cm}$ were ultrasonically cleaned in acetone followed by de-ionized water and finally dried using nitrogen blower. Air dried substrates were kept in the quartz boat, which was then placed at the centre of the quartz tube. One end of the quartz tube was attached to the spray nozzle and other to the gas bubbler. The quartz tube was first flushed with argon gas in order to eliminate air from the quartz tube and then heated to a reaction temperature. Glycine max oil and ferrocene mixture was sprayed into the quartz tube using Ar gas. The concentration of ferrocene in carbon source was $25 \mathrm{mg} / \mathrm{mL}$. The experiments were carried out at the temperature of $650{ }^{\circ} \mathrm{C}$. After deposition, deposited material was annealed for $10 \mathrm{~min}$ at the same temperature and allowed to cool down to room temperature under the same Ar gas flow. The black deposition in the form of carbon soot was removed from the quartz tube. As grown vertically aligned carbon nanotubes were characterized using SEM, TEM, XRD, Raman spectroscopy and TGA analysis. The experiments were repeated several times to ensure the reproducibility of the formation of vertically aligned carbon nanotubes.

As grown vertically aligned CNTs were characterized using a scanning electron microscope and transmission electron microscope (Hitachi-3000H, Japan and JEM-2010F TEM). Raman spectroscopy was carried out by a JASCO NRS-1500 w with a green laser excited on wavelength of $532 \mathrm{~nm}$. Thermo gravimetric analysis (TGA) was performed on EXSTAR 6200 thermal analyzer at $10{ }^{\circ} \mathrm{C}$ per min from room temperature to $900{ }^{\circ} \mathrm{C}$ in air. X-ray diffraction measurements were performed with Burker AXS D8 Advance using copper radiation.

\section{RESULTS AND DISCUSSION}

Microstructural investigations of as grown samples were carried out using SEM and TEM techniques. Figure 1 shows SEM image of densely packed vertically aligned CNTs grown on a silicon substrate, which was a typical product obtained at a temperature of $650{ }^{\circ} \mathrm{C}$ with $30 \mathrm{~min}$ deposition time. The image shows the growth of carbon nanotubes seems to be uniform and reaches up to a length of ten $\mu \mathrm{m}$. The image in Figure $1 \mathrm{~b}$ shows a side view of the aligned CNTs that was peeled off from the substrate. The $\mathrm{Si}$ substrate have advantage to have native $\mathrm{SiO}_{2}$ layer which is strong support and catalytic activity with carbon atoms helps nanotubes grow longer [31]. The high surface density of the growing nanotubes serves as an additional advantage for the constituent nanotubes to be uncoiled.

Figure 2 shows the TEM images of CNTs grown at $650^{\circ} \mathrm{C}$. It can be noticed that amorphous carbon and metal particles are nearly absent. The high-resolution TEM images of as grown vertically aligned CNTs are shown in the Figure 2b. HRTEM image in Figure $2 b$ reveals wellgraphitized CNTs with inner and outer diameters are about 10 and $30 \mathrm{~nm}$, respectively. Most of the CNTs had both closed ends and the tube walls are often bridged. The CNTs have a multiwalled structure with a hollow inside the CNTs. Conversely, as grown nanotubes show some defects over long range (Figure 2a). 

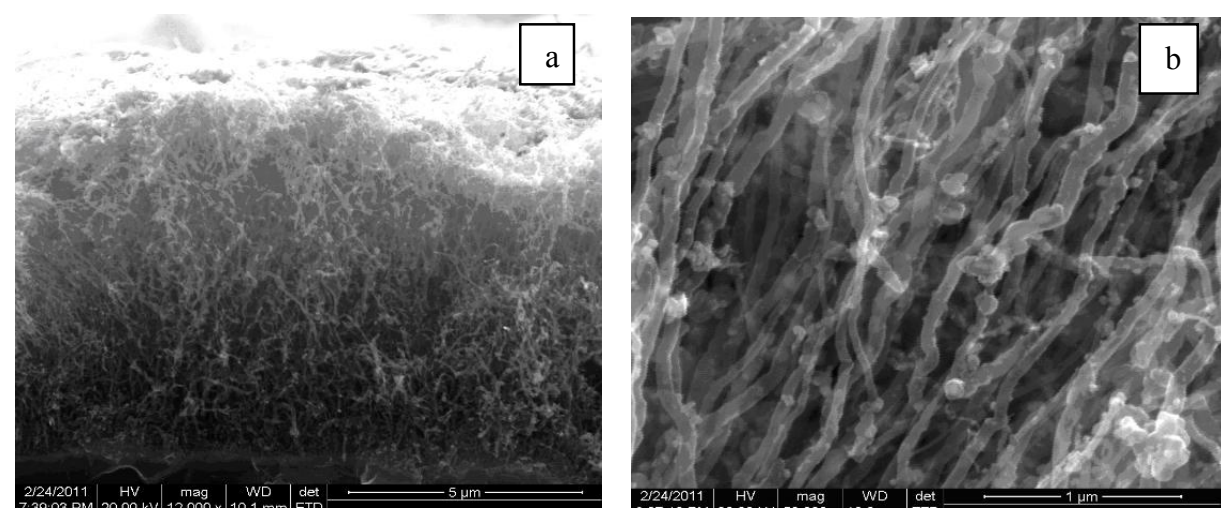

Figure 1. SEM images of VACNT grown on Si substrate (a) as-grown aligned CNT and (b) side view of the aligned CNTs.
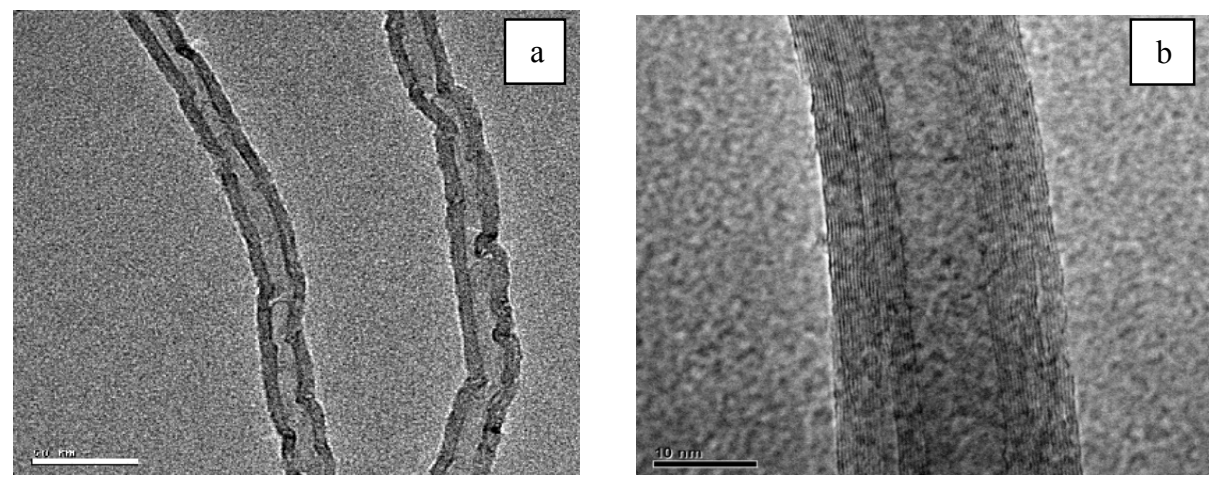

Figure 2. TEM images of VACNT grown on Si substrate (a) tem image of aligned CNT and (b) magnified image of aligned CNTs.

Raman spectroscopy is an important tool for studying CNTs samples, which provides information about the structure and the presence of disorder in the sample. Raman spectroscopy was performed with a green laser excited on wavelength of $532 \mathrm{~nm}$. Figure 3 shows typical Raman spectra of vertically aligned CNTs on silicon substrates indicating two characteristic peaks. The $\mathrm{G}$ and $\mathrm{D}$ peaks were prominent at 1577.33 and $1351.45 \mathrm{~cm}^{-1}$, respectively. The Gband corresponds to the tangential stretching mode of highly oriented pyrolytic graphite and suggests the CNTs are composed of crystalline graphitic carbon. D-Peak due to structural defects of the graphite crystal [32]. $\mathrm{G}^{1}$ band at $2696.56 \mathrm{~cm}^{-1}$ is a second order of two phonon process. Generally $\mathrm{I}_{\mathrm{D}} / \mathrm{I}_{\mathrm{G}}$ can be used as an indicator of the extent of defect or disorder within the nanotubes. The $\mathrm{I}_{\mathrm{D}} / \mathrm{I}_{\mathrm{G}}$ value of as grown CNTs is 0.858 . Generally, lower $\mathrm{I}_{\mathrm{D}} / \mathrm{I}_{\mathrm{G}}$ value indicates a higher degree of graphitization [33].

The as grown CNT sample was characterized by XRD. Figure 4 shows the XRD-pattern of CNTs grown at $650{ }^{\circ} \mathrm{C}$. The intense peak at $26.164^{\circ}$ and $44.658^{\circ}$ are indexed to be the $(002)$ and (101) reflections of hexagonal graphite. 


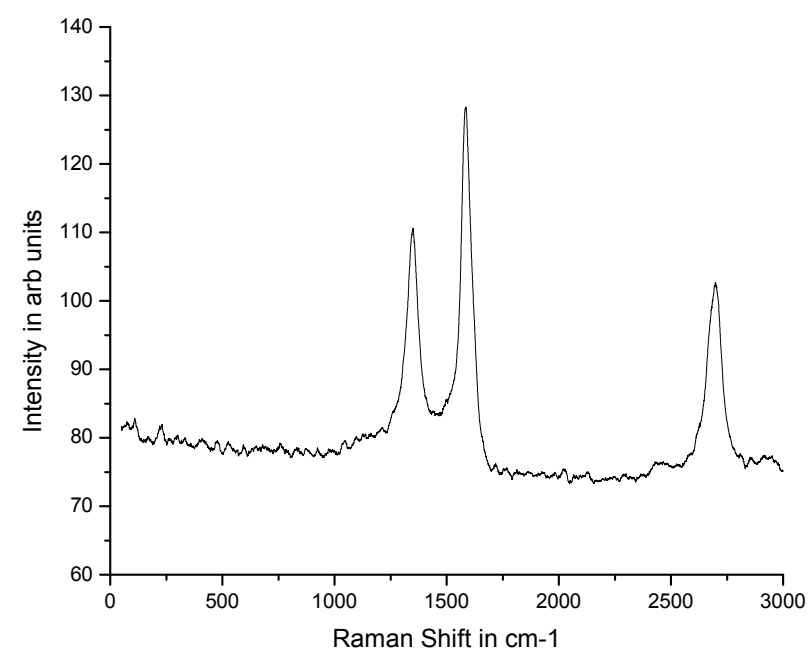

Figure 3. Raman spectrum of as-grown aligned CNTs at $650^{\circ} \mathrm{C}$.

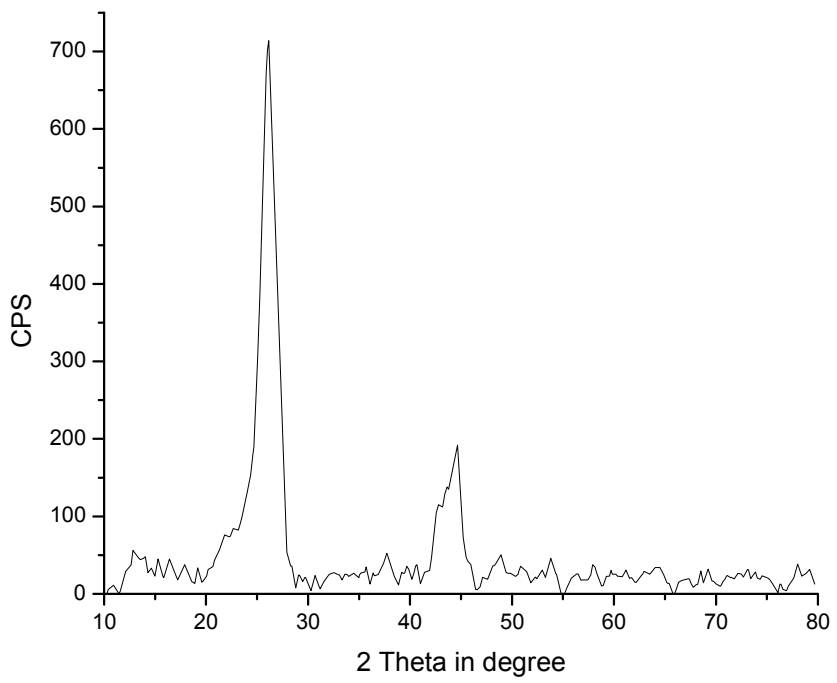

Figure 4. XRD spectrum of as-grown aligned CNTs at $650^{\circ} \mathrm{C}$.

Thermogravimetric analysis is a very useful technique in determining the degree of crystallinity of the as-grown nanotubes. Quality and purity of the vertically aligned CNTs were studied using TGA analysis (Figure 5). Initial weight loss up to approximately $480{ }^{\circ} \mathrm{C}$ was attributed to a low content of amorphous carbon and the significant weight loss occurs around $630{ }^{\circ} \mathrm{C}$ was due to the oxidative decomposition of vertically aligned CNTs. The TGA results

Bull. Chem. Soc. Ethiop. 2017, 31(2) 
reveal that the content of the vertically aligned CNTs with a high degree of graphitization is $80 \%$ in the product.

Ferrocene undergoes thermal decomposition at high temperature forms Fe nanoparticles on the surface of silicon substrate. Carbon precursor is catalytically decomposed and the carbon fragments formed diffused into the nanosized $\mathrm{Fe}$ particles settled on the Si substrate in the synthesis region. The Fe particles may thus easily become saturated or supersaturated with carbon atoms, and the precipitation of the carbon from the surface of the Fe particle leads to the formation of dense carbon nanotubes. As the catalyst film becomes thicker, the interaction between the nanotube walls induces the growth of CNTs in with a straight form that is parallel to the substrate. The overcrowding of the CNTs in the array forces the tubes to grow vertically [34]. Majority of the articles agree with the mechanism of alignment elucidated by Fan and coworkers which is simply caused by the van der Waals force [12]. The strong interaction of the van der Waals force enables the CNTs bound together to form dense ordered packing. Thus ferrocene can effectively catalyze the growth of highly dense vertically aligned carbon nanotubes on the silicon substrate using Glycine max oil.

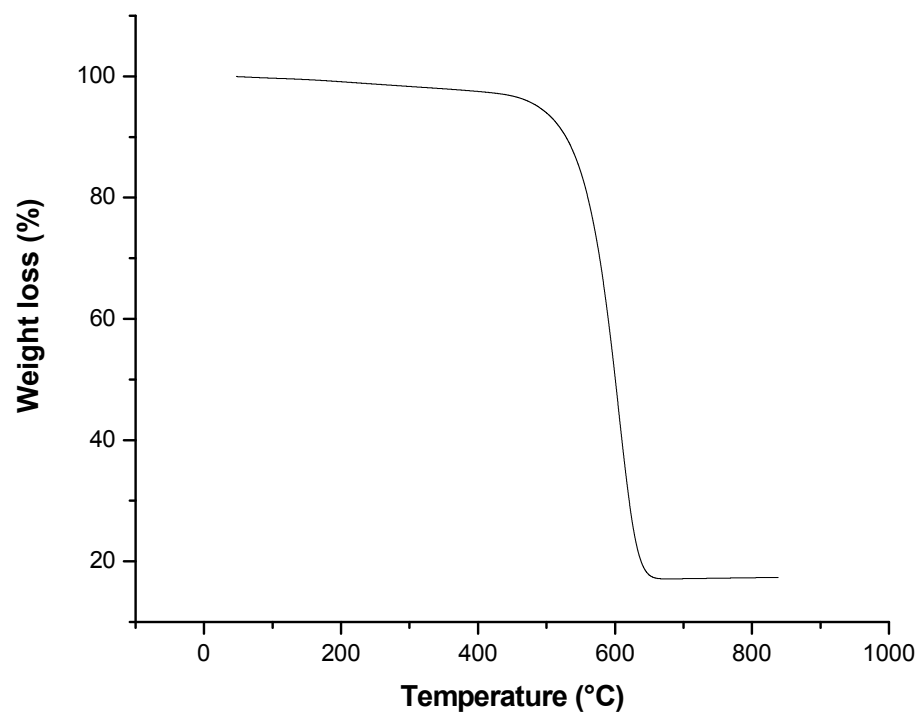

Figure 5. TGA curve of as-grown aligned CNTs.

\section{CONCLUSION}

Synthesis of vertically aligned carbon nanotubes have been demonstrated using Glycine max oil as an efficient, economical and environment friendly carbon source and $\mathrm{Fe}$ nanoparticles derived from the decomposition of ferrocene as the catalyst at $650^{\circ} \mathrm{C}$ under an Ar atmosphere by spray pyrolysis. The as grown vertically aligned CNTs have an outer diameter of 10-30 nm. It was found that the present technique gives a higher yield and high density of vertically aligned CNTs. 


\section{ACKNOWLEDGMENTS}

The authors acknowledge the UGC New Delhi for financial support, the Institute for Environmental and Nanotechnology for technical support and IITM for access to electron microscopes.

\section{REFERENCES}

1. Feng, W.; Bai, X.D.; Lian, Y.Q.; Liang, J.; Wang, X.G.; Yoshino, K. Well-aligned polyaniline/carbon-nanotube composite films grown by in-situ aniline polymerization. Carbon 2003, 41, 1551-1557.

2. Morassutto, M.; Tiggelaar, R.M.; Smithers, M.A.; Gardeniees, J.G.E. Vertically aligned carbon nanotube field emitter arrays with ohmic base contact to silicon by Fe-catalyzed chemical vapor deposition. Mater. Today commun. 2016, 7, 89-100.

3. Gavalas, V.G.; Andrews, R.; Bhattacharyya, D.; Bachas, L.G. Carbon nanotube sol-gel composite materials. Nano lett. 2001, 1, 719-721.

4. Tarntair, F.G.; Chen, L.C.; Wei, S.L.; Hong, W.K.; Chen, K.H.; Cheng, H.C. High current density field emission from arrays of carbon nanotubes and diamond-clad Si tips. J. Vac. Sci. Technol. B 2000, 18, 1207-1211.

5. Yang, L.; Xu. Y.; Wang, X.; Zhu,J.; Zhang, R.; He, P.; Fang, Y. The application of $\beta$ cyclodextrin derivative functionalized aligned carbon nanotubes for electrochemically DNA sensing via host-guest recognition. Anal. Chim. Acta 2011, 689, 39-46.

6. Dogru. I.B.; Durukan. M.B.; Turel. O.; Unalan. H.E. Flexible supercapacitor electrodes with vertically aligned carbon nanotubes grown on aluminium foils. Prog. Nat. Sci.2016, 26, $232-$ 236.

7. Yang, J.; Zhang, R.; Xu, Y.; He, P.; Fang, Y. Direct electrochemistry study of glucose oxidase on Pt nanoparticle-modified aligned carbon nanotubes electrode by the assistance of chitosan-CdS and its biosensoring for glucose. Electrochem. Commun. 2008, 10, 1889-1892.

8. Zhang, W.-D.; Xu, B. A solid-state $\mathrm{pH}$ sensor based on $\mathrm{WO}_{3}$ modified vertically aligned multiwalled carbon nanotubes. Electrochem. Commun. 2009, 11, 1038-1041.

9. Penza, M.; Rossi, R.; Alvisi, M.; Signore, M.A.; Cassano, G.; Dimaio, D.R.; Pentassuglia, E.; Piscopiello, E.; Serra, M.; Falconieri, M. Characterization of metal-modified and vertically-aligned carbon nanotube films for functionally enhanced gas sensor applications. Thin Solid Films 2009, 517, 6211-6216.

10. In, J.B.; Kwon, H.J.; Yoo, J.H.; Allen, F.I.; Minor, A.M.; Grigoropoulos, C.P. Laser welding of vertically aligned carbon nanotube arrays on polymer work piece. Carbon 2017, 115, 688-693.

11. Thess, A.; Lee, R.; Nikolaev, P.; Dai, H.; Petit, P.; Robert, J.; Xu, C.; Lee, Y.H.; Kim, S.G.; Rinzler, A.G.; Colbert, D.T.; Scuseria, G.E.; Tomanek, D.; Fischer, J.E.; Smalley, R.E. Crystalline ropes of metallic carbon nanotubes. Science 1996, 273, 483-487.

12. Fan, S.; Chapline, M.G.; Franklin, N.R.; Tombler, T.W.; Cassell, A.M; Dai, H. Self-oriented regular arrays of carbon nanotubes and their field emission properties. Science 1999, 283, 512-514.

13. Murakami, Y.; Chiashi, S.; Miyauchi, Y.; Hu, M.; Ogura, M.; Okubo, T.; Maruyama, S. Growth of vertically aligned single-walled carbon nanotube films on quartz substrates and their optical anisotropy. Chem. Phys. Lett. 2004, 385, 298-303.

14. Taei, M.; Hasanpour, F.; Zahedi, G. Growth mechanism of vertically aligned carbon nanotubes on silicon substrates. Synth. Met. 2001, 117, 81-86.

15. Taei, M.; Hasanpour, F.; Zahedi, G. Application of new ferrocene derivative electrocatalytic determination of captopril using multiwall carbon nanotube modified carbon paste electrode. Bull. Chem. Soc. Ethiop. 2015, 29, 149-156. 
16. Cao, A.; Zhang, X.; Xu, C.; Liang, J.; Wu. D.; Chen, X.; Wei, B.; Ajayan, P.M.; Grape vinelike growth of single walled carbon nanotubes among vertically aligned multiwalled nanotube arrays. Appl. Phys. Lett. 2001, 79, 1252-1253.

17. Rao, C.N.R.; Sen, R.; Sathishkumar, B.C.; Govindaraj. A. Large aligned-nanotube bundles from ferrocene pyrolysis. Chem. Commun. 1998, 1525-1526.

18. Palizdar, M.; Ahgababazadeh, R.; Mirhabibi, A.; Brydson, R.; Pilehvari, S. Investigation of $\mathrm{Fe} / \mathrm{MgO}$ catalyst support precursors for the chemical vapour deposition growth of carbon nanotubes. J. Nanosci. Nanotechnol. 2011, 11, 5345-5351.

19. Tomie, T.; Inoue, S.; Kohno, M.; Matsumura, Y. Prospective growth region for chemical vapor deposition synthesis of carbon nanotube on C-H-O ternary diagram. Diamond Relat. Mater. 2010, 19, 1401-1404.

20. Narkiewicz, U.; Podsiadly, M.; Jedrzejewski, R.; Pelech, I. Catalytic decomposition of hydrocarbons on cobalt, nickel and iron catalysts to obtain carbon nanomaterials. Appl. Catal. A Gen. 2010, 384, 27-35.

21. He. D.L.; Li. H.; Li. W.; Haghi-Ashitani. P.; Lejay. P.; Bai. J. Growth of carbon nanotubes in six orthogonal directions on spherical alumina microparticles. Carbon 2011, 49, 22732286.

22. Shirazi, Y.; Tofighy, M.A.; Mohammadi, T.; Pak, A. Effects of different carbon precursors on synthesis of multiwall carbon nanotubes: Purification and functionalization. Appl. Surf. Sci. 2011, 257, 7359-7367.

23. Yong, Z.; Fang, L.; Zhi-hua, Z. Synthesis of heterostructured helical carbon nanotubes by iron-catalyzed ethanol decomposition. Micron 2011, 42, 547-552.

24. Kumar, M.; Ando, Y. A simple method of producing aligned carbon nanotubes from an unconventional precursor-camphor. Chem. Phys. Lett. 2003, 374, 521-526.

25. Karthikeyan, S.; Mahalingam,P. Studies of yield and nature of multi-walled carbon nanotubes synthesized by spray pyrolysis of pine oil at different temperatures. Int. J. Nanotechnol. Appl. 2010, 4, 189-197.

26. Mageswari, S.; Kalaiselvan, S.; Syed Shabudeen, P.S.; Sivakumar, N.; Karthikeyan, S. Optimization of growth temperature of multi-walled carbon nanotubes fabricated by chemical vapour deposition and their application for arsenic removal. Mater. Sci. Poland 2014, 32, 709-718.

27. Mahalingam, P.; Sivakumar, N.; Karthik, M.; Karthikeyan, S. Characterization of magnetic metal encapsulated in multi-walled carbon nanotubes synthesized from methyl ester of Pongamia pinnata oil and its application for removal of arsenic ions from aqueous solution. Asian J. Chem. 2014, 26, 4167-4171.

28. Ghosh, P.; Afre, R.A.; Soga, T.; Jimbo, T. A simple method of producing single-walled carbon nanotubes from a natural precursor: Eucalyptus oil. Mater. Lett. 2007, 61, 37683770 .

29. Afre, R.A.; Soga, T.; Jimbo, T.; Kumar, M.; Ando, Y.; Sharon, M. Growth of vertically aligned nanotubes on silicon and quartz substrate by spray pyrolysis of a natural precursor. Chem. Phys. Lett. 2005, 414, 6-10.

30. Angulakshmi, V.S.; Sathiskumar, C.; Karthik, M.; Karthikeyan, S. Synthesis of multiwalled carbon nanotubes from Glycine max oil and their potential applications. J. Environ. Nanotechnol. 2013, 2, 101-106.

31. Zhang, Z.J.; Wei, B.Q.; Ramnath, G.; Ajayan, P.M. Substrate-site selective growth of aligned carbon nanotubes. Appl. Phys. Lett. 2000, 77, 3764-3766.

32. Costa, S.; Borowiak-Palen, E.; Kruszynska, M.; Bachmatiuk, A; Kalenczuk, R. J. Characterization of carbon nanotubes by Raman spectroscopy. Mater Sci. Poland 2008, 26, 433-441. 
33. Hintsho, N.; Shaikjee, A.; Masenda, H.; Naidoo, D.; Billing, D.; Franklyn, P.; Durbach. S. Direct synthesis of carbon nanofibers from South African coal fly ash. Nanoscale Res. Lett. 2014, 9, Article 387.

34. Zhang, W.D.; Wen, Y.; Liu, S.M.; Tjiu, W.C.; Xu, G.Q.; Gan, L.M. Synthesis of vertically aligned carbon nanotubes on metal deposited quartz plates. Carbon 2002, 40, 1981-1989. 